\title{
MENINGEAL LIPOMAS IN THE FORAMEN MAGNUM
}

\author{
BY \\ WALTER MISCH, LONDON
}

LIPomas rarely develop in the meninges. Within the skull the favourite site of the lipomas is the dorsal surface of the corpus callosum ; the region of the tuber cinereum and the midbrain seem to be frequent sites, although much less so than the corpus callosum. Sometimes they are associated with malformations of the brain, especially with defects of the corpus callosum. Most of the lipomas in the skull do not cause symptoms and are found incidentally at necropsy (Bailey).

About their origin there are many theories : (a) that they arise from lipoid cells already present in the pia mater; (b) that they arise by fatty transformation of the connective tissue ; $(c)$ that they arise by differentiation of the pial cells towards an embryonic form, with a subsequent metaplasia into fat ; $(d)$ that they arise from embryonal remnants (Verga).

The last lists of lipomas found in the central nervous system are in the papers of v. Sury and of Verga, which is a kind of monograph on the lipomas of the pia mater. Large lipomas at the base of the brain with distinct symptoms and signs have been described (Hirtz, Klob, Shaw). But most of these tumours did not cause any symptoms, even when they were situated near the foramen magnum. Only a few lipomas have been described in this area; and their clinical picture has been ignored or the description has been brief.

The first was described by Cruveilhier (1856, quoted by Bostroem and others) on the left side of the medulla in the olive beneath the arachnoid ; although it was of the size of a pea it did not produce any symptoms. In a case of Leyden (a female, aged 28 years) a lipoma on the foramen magnum, bulging towards the pons and medulla, caused symptoms of vertigo, hemiparesis of the left side with pains in the left limbs, disturbances of speech and swallowing; in this case the right sixth and tenth nerves were found atrophied and the medulla softened.

The other few cases described in this region were either enchondromata (Bostroem, Bälz) or not well-defined tumours (Gowers, Wätzoldt).

The two lipomas of the foramen magnum to be reported here * seem to be the first ones with a long-standing history and with repeated clinical

* Seen in the Neuköllner Krankenhaus in Berlin in 1928 and 1931. 
examinations, one case being extrameningeal, the other intrameningeal. During life the exact diagnosis could not be made out, although in the second case it was suspected because of its resemblance to the first one.

\section{PERSONAL GASES}

Case 1.-S.P., age 14. Admitted July 4, 1928.

History.-About one and a half years ago (end of 1926), fall on her head ; not unconscious, no sequelæ whatever, apart from a slight headache for a short time. Sixteen months ago (March, 1927), severe frontal headache, present all day and night, with vomiting, and increasing gradually. Twelve months ago (July, 1927), unsteadi-

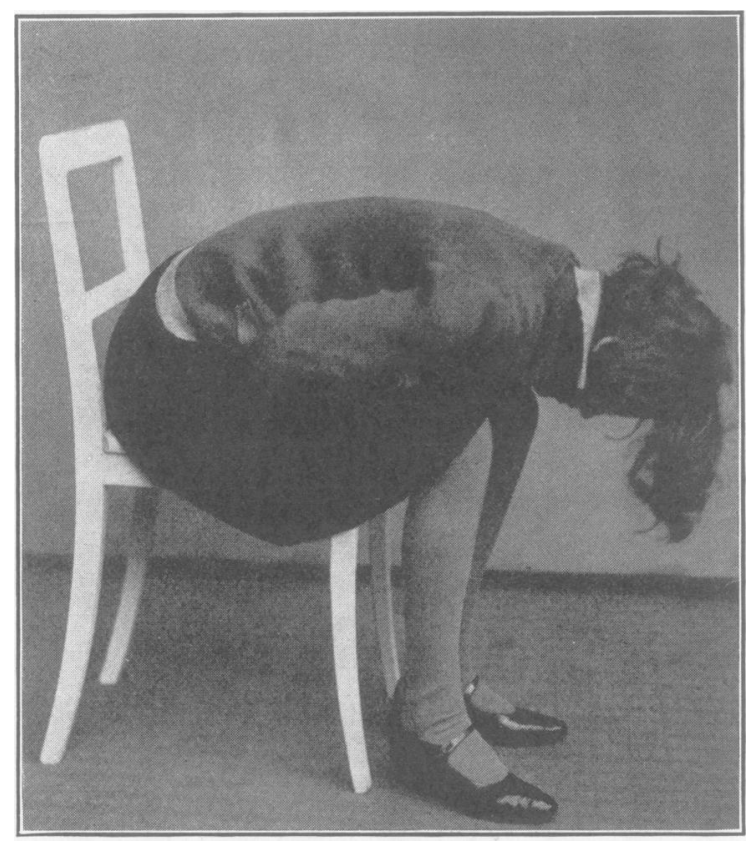

CASE I.-Favourite attitude for better breathing.

ness of gait. Ten months ago, double vision in the form of a horizontal diplopia. Later, neck rigidity. A few weeks later, vertigo, difficulty in swallowing ; dysarthria ; paræsthesiæ third and fourth fingers of right hand. Again, a few weeks later, paræsthesiæ of right arm, retention of urine, sensation of a node in rectum. For about six months, increasing speech trouble, signs of recurrent paralysis.

Neurological Examination, December, 1927 (Prof. A. Simons).-Dises normal. Pupils equal in size and reacting normally to light and convergence. Eye movements normal. Nystagmus, slow to the right side, less marked to the left. Corneal reflexes absent on both sides. Depression of sensibility both for light touch and for pin-prick all over the trigeminal area on both sides ; hyperæsthesia for pain-stimuli round the mouth. No facial weakness. Eighth nerve normal in both portions. Right palatal paresis. Phonation defective. Upper extremities : hypotonic, but no motor paresis ; reflexes normal; dysmetria left hand. Abdominal reflexes doubtful. Lower extremities 
hypotonic in passive movements. Both knee- and ankle-jerks present and equal, brisk, no true spastic signs. No ataxia. Hemianæsthesia for pain-stimuli right side. Romberg's sign markedly positive ; constant tendency to fall to the left side. Constant deviation to the left in walking, with trunk bent to the left. In the sitting
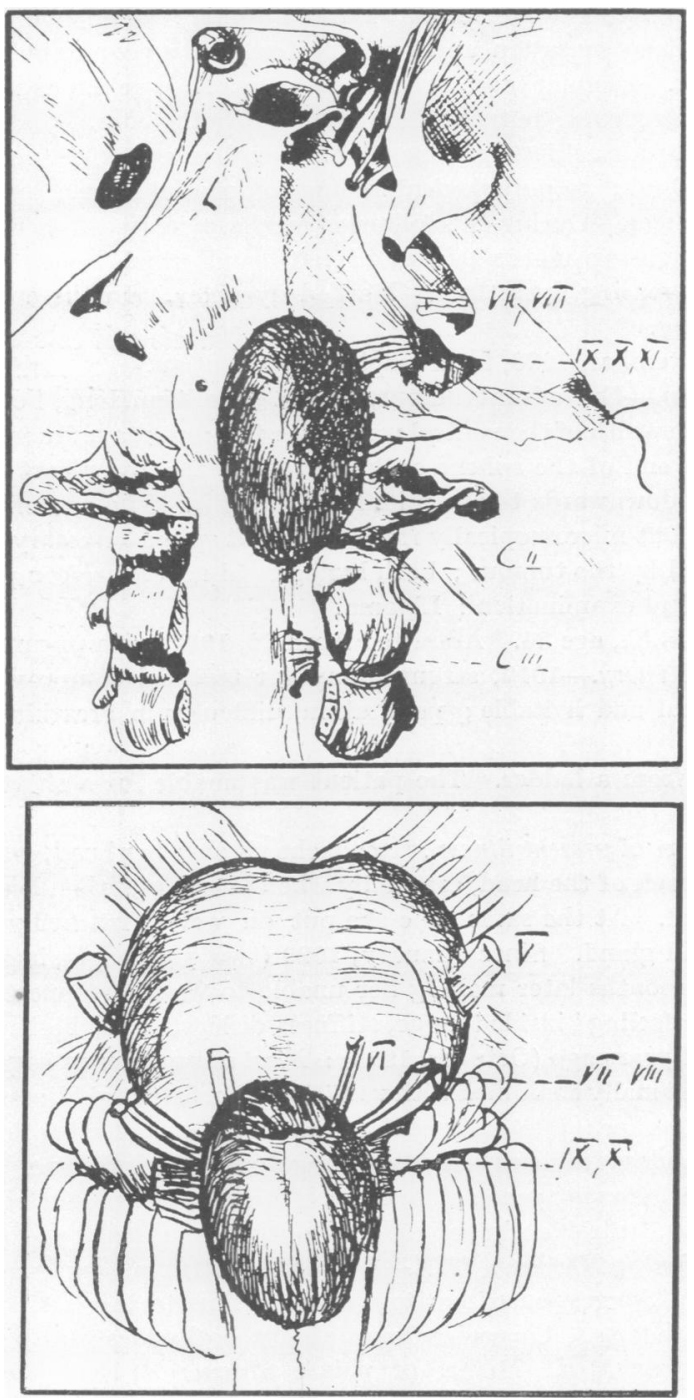

CASE I.-Extradural lipoma.

position slight deviation of trunk to the right and backwards. Fixed deviation of head towards left shoulder. Nasal articulation. No aphasia, no apraxia.

Neurological Re-examination, July, 1928.-Left pupil larger than right. Discs normal. Corneal reflexes absent. Eye movements full, no diplopia. Nystagmus to the right, sustained and slow; to a lesser degree nystagmus to the left. Left 
facial weakness of peripheral type, more marked in upper part of face. Early muscular wasting in left half of tongue, some fibrillary twitchings. Paresis of right palate. Dysarthric speech, difficulty in swallowing. Anæsthesia for temperature both trigeminal areas, with sparing of a zone round the mouth. Upper limbs : flaccid paralysis of right arm, with considerable wasting of hand-muscles and muscles of forearm; early muscular wasting of left hand. Marked ataxia ; adiadochokinesis in right arm. Depression of deep sensation and sense of temperature in right hand. Abdominal reflexes absent. Bladder and rectal tenesmus. Lower limbs : paraparesis with normal tendon reflexes, but extensor response both sides. Cervical opisthotonus, Kernig's and Brudzinski's signs positive. Lumbar puncture produced only a few drops of clear fluid ; no pathological findings on examination.

Progress Notes.-During the following weeks increase of occipital headache and vomiting. Increasing motor paresis of left hand which became gradually almost paralysed. Increasing dysarthria. Marked dyspnœa. In the end marked CheyneStokes breathing.

Death, September, 1928, from respiratory cessation.

Post-mortem.-Extradural tumour, $2.5 \mathrm{~cm}$. wide, $4 \mathrm{~cm}$. long, $1 \mathrm{~cm}$. thick, extending across the whole width of the ventral wall of the foramen magnum (clivus); originating from the lower end of the spheno-occipital region, the lower part of which it covers, and prolonged downwards to the middle of the axis. The medulla is compressed in its upper part, but microscopically free ; the right spinal accessory nerve is displaced, but not invaded by the tumour; both hypoglossal nerves are compressed.

Microscopical examination : Lipoma.

Case 11.-E.N., age 34. Admitted April 22, 1931, with pneumonia.

Previous History.-1912, strumectomy for tracheal compression. Was always rather emotional and irritable ; palpitation, difficulty in breathing, especially when climbing. head.

1925, fall from a ladder. The patient was unable for a short time to turn her

1927.-Start of present illness : Headache all over her head, gradually increasing. First only on back of the head, especially when laughing; then headache in forehead and top of head. At the same time she put on weight markedly ; further enlargement of thyroid gland. Since January, 1929 (two years ago), increasing vertiginous attacks, some months later making her unable to walk unsupponted. Since March, 1929, a ' heavy feeling' inside tongue, stiffness of legs, paræsthesiæ in hands and face. One and a half years ago (October, 1929) : First observation in hospital : Very severe headache, occasionally combined with vomiting ; persistent giddiness, speech difficulty, cold sensation in face ; pins and needles in hands ; heavy feeling in all limbs ; double vision to both sides ; difficulty in swallowing; retention of urine.

During the following year : difficulties of speech and swallowing, as well as paresis of legs and arms, bedridden in the end ; incontinence of fæces and urine.

Examination in October, 1929.-Adiposity, struma, tachycardia. Fundi and pupils normal. Suggestion of horizontal nystagmus to the left. Speech dysarthric and somewhat hoarse. Corneal reflexes absent both sides; fifth otherwise normal. Jaw reflex exaggerated. Reflex of palate absent. Muscular wasting of tongue muscles both sides, right side more marked and with definite fibrillary twitchings. Slight deviation of tongue to the right. R.D. in right half of tongue. Abdominal reflexes absent. Tendon reflexes of lower limbs exaggerated; knee-jerk brisker right side. Flexion in hip-joint right side weaker than left. Coordination of arms and legs slightly impaired. Marked static ataxia. Romberg's test with constant falling to the right. Special examination showed no pathological finding of the vocal cords and of the vestibular apparatus. Lumbar puncture : slight increase of globulin. 
Re-examination on admission to hospital on April 22, 1931.-Marked spastic tetraparesis with exaggerated tendon reflexes. Babinski left side. Sitting, the patient is unable to keep her head in position. Headache in back of head in region of upper cervical spine. Rotatory quick nystagmus to all directions. Marked dysarthria.
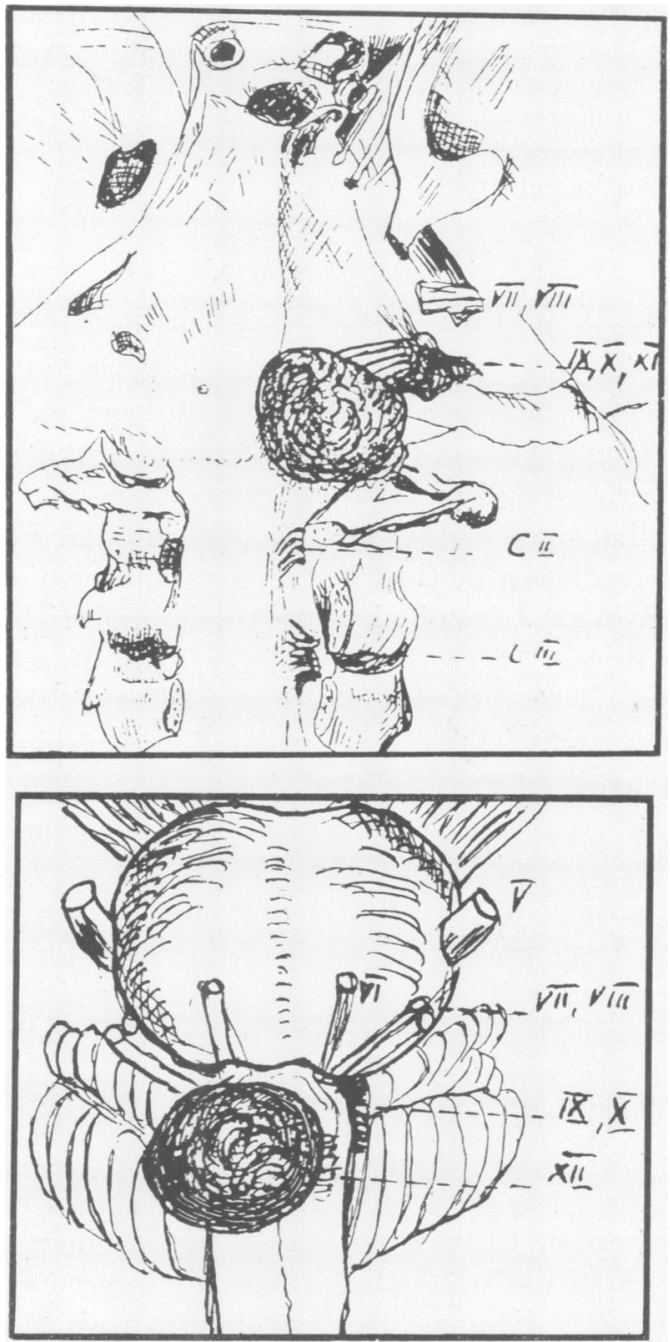

CASE II.-Intradural lipoma.

Paralysis of tongue with atrophy both sides. Paralysis of soft palate with total paresis of swallowing. Sensory depression over both cheeks and round mouth of segmental distribution and perfectly symmetrical. Corneal reflex absent left side, right side only depressed. Otherwise no sensory finding. Recurrent paralysis. Fundi normal.

Death from bronchopneumonia on April 25, 1931.

Post-mortem.-Intradural tumour, $2.5 \mathrm{~cm}$. wide, $1.7 \mathrm{~cm}$. long, $2.2 \mathrm{~cm}$. thick, consisting of several small lobules, firm and elastic, yellowish and transparent, with 
branching vessels on the surface. It fills the greater part of the right side of the foramen magnum, at its widest part reaching only a short distance to the left of the midline. The tumour is a little obliquely placed and lying from left above to right below between the sella turcica and the foramen magnum (clivus), so that above it reaches to the level of the upper margin of the jugular foramen and below to a little below the atlantooccipital articulation, on the right almost to the jugular foramen $(2.0 \mathrm{~cm}$. wide), on the left to about $0.5 \mathrm{~cm}$. over the midline. The medulla is much displaced to the left, and from the beginning of the pons downwards it is flattened in its right half. The cerebellum also is depressed, chiefly on the right and a little to the left of the midline. Both hypoglossal nerves are compressed.

Microscopical examination : Lipoma.

\section{DISGUSSION}

Both cases began with headache either occipital or frontal, vertigo and unsteadiness of gait.

In the first case, where an extradural lipoma covered the ventral side of the whole medulla and parts of the lower pons and of the upper cervical cord, there were first horizontal diplopia and later neck rigidity, followed by vertigo, symptoms of bulbar paralysis (dysarthria, difficulty in swallowing), bladder disturbances, paræsthesiæ in the right fingers and arm as well as signs of cerebellar disturbances, trigeminal hypæsthesia and right hemianæsthesia. Finally came paraplegia with atrophy of the hand muscles, atrophy of the left tongue, paresis of the left seventh, disturbances of the fifth, and Horner's syndrome on the right. Death occurred from respiratory paralysis 18 months after the onset of the condition.

In the second case, where a thick intradural lipoma covered the right ventral side of the upper part of the depressed and displaced medulla, there was a rapid appearance of cerebellar symptoms (vertigo, gait disturbances), followed by slow development of paresis of the lower limbs and paræsthesiæ in hands and face, as well as atrophy of the tongue (right more than left) with dysarthria and absence of corneal reflexes. Finally came increasing cerebellar and bulbar signs and development of tetraparesis with bladder and rectum incontinence. Death occurred from bronchopneumonia four years after the onset of the disease.

Comparing the symptoms and signs of these cases with those of other tumours of this region, there is no characteristic difference as regards the great variability in site of the extrabulbar tumours. Corresponding to the more mesial site of the lipomas the developing paresis seems to be bilateral from the beginning.

Headache and cerebellar disturbances were the first symptoms. Papillœdema was not found.

\section{REFERENCES}

BAILEY, Intracranial Tumours, 1933, 354.

BäLz, Arch.f. Kinderheilk., 1872, 13.

Boström, Centralbl. f. allg. Pathol., 1897, 8, 1. 
Cruveilhier, Traité d'anat. pathol. générale, 1856, 3, 312.

Gowers and WÄtzoldt. Quoted by Lewandowsky, Handbuch d. Neurologie, 3, 615. Hintz, Bull. de la soc. d'anat. de Paris, 1875, 254.

Kцов, Zeits. d. k. k. Gesellsch. d. Aerzte zu Wien, 1859, 673.

v. LEYDEN, Klinik d. Rückenmarkskrankheiten, $2,155$.

v. Sury, Frankf. Zeitschr. f. Pathol., 1907, 1, 485.

Shaw, Brit. Med. Journ., 1896, 1828.

Verga, P., Tumoti, 1929, 3, 321. 